\title{
USO DA ACIDEZ TITULÁVEL NO CONTROLE DE QUALIDADE DO LEITE HUMANO ORDENHADO ${ }^{1}$
}

\author{
Jorge Luís Pereira CAVALCANTE ${ }^{2, *}$, Francisco José Siqueira TELLES ${ }^{2}$, \\ Maria Marly Lopes Vieira PEIXOTO³, Rita de Cássia de Barros RODRIGUES ${ }^{3}$
}

\section{RESUMO}

O perfil fisico-químico do leite humano ordenhado cru (LHOc) com acidez titulável acima de $7^{\circ} \mathrm{D}$ após 15 dias de congelamento, teores de creme, gordura total e valor energético, foram avaliados. Na etapa controle, os valores absolutos de creme, gordura total e valor energético $(n=3887)$ foram determinados pelo método do crematócrito e a acidez titulável $(n=4204)$ do LHOc por um método titulimétrico adaptado de leite de vaca. Na etapa teste, determinou-se o teor de creme, gordura total e valor energético de amostras ( $\mathrm{n}=66$ ) com acidez acima de $7^{\circ} \mathrm{D}$ armazenadas entre $-10^{\circ} \mathrm{e}-18^{\circ} \mathrm{C}$ por 15 dias. A acidez titulável variou de 0,5 a $21^{\circ} \mathrm{D}\left(3,52 \pm 2,45^{\circ} \mathrm{D}\right)$ e os teores de creme, gordura total e valor energético foram, respectivamente, 4,90 $\pm 0,25 \%, 4,49 \pm 0,26 \%$ e 617,47 $\pm 17,37 \mathrm{Kcal} /$ Litro. Houve redução significante nos teores de creme $(6,45 \pm 2,28 \%$ para $5,79 \pm 2,57 \%)$, gordura total $(4,0 \pm 1,81 \%$ para $3,49 \pm 1,76 \%)$ e valor energético $(716,27 \pm 176,59 \mathrm{Kcal} /$ Litro para $666,82 \pm 171,90 \mathrm{Kcal} /$ Litro), com $\mathrm{p}<0,05$. O uso do teste da acidez titulável constitui uma ferramenta importante no controle de qualidade do LHOc.

Palavras-chave: leite humano ordenhado; acidez titulável; lipídios; crematócrito; congelamento; banco de leite humano.

\section{SUMMARY}

USE OF THE TITRATABLE ACIDITY IN THE QUALITY CONTROL OF THE MILKED HUMAN MILK. The physiochemical profile of the human milk milked raw (HMMr) with titratable acidity above $7^{\circ} \mathrm{D}$ after 15 days of freezing, the tenors of cream, total fat and energy value was determinated. In the control step, the absolute values of cream, total fat and energy value $(\mathrm{N}=3887)$ were determinated for the method of the creamatocrit, and the titratable acidity $(\mathrm{N}=4204)$ of the HMMr were determined for a method adapted of cow milk. In the test step, there was determined the tenor of cream, total fat and energy value of samples $(n=66)$ with acidity above $7^{\circ} \mathrm{D}$ stored between $-10^{\circ} \mathrm{C}$ and $-18^{\circ} \mathrm{C}$ by 15 days. The titratable acidity varied from 0.5 to $21^{\circ} \mathrm{D}\left(3.52 \pm 2.45^{\circ} \mathrm{D}\right)$, and the tenors of cream, total fat and energy value were, respectively, $4.90 \pm 0.25 \%, 4.49 \pm 0.26 \%$ and $617.47 \pm 17.37 \mathrm{Kcal} /$ Liter. There was significant reduction in the tenors of cream $(6.45 \pm 2.28 \%$ for $5.79 \pm 2.57 \%)$, total fat $(4.0 \pm 1.81 \%$ for $3.49 \pm 1.76 \%)$ and energy value $(716.27 \pm 176.59 \mathrm{Kcal} / \mathrm{Liter}$ for 666.82 $\pm 171.90 \mathrm{Kcal} /$ Liter) with $\mathrm{p}<0.05$. The use of the test of the titratable acidity constitutes one important tool in the quality control of the HMMr.

Keywords: human milk milked; titratable acidity; lipids; creamatocrit; freezing; human milk bank.

\section{1 - INTRODUÇÃO}

O leite humano (LH) é o único alimento energético, nutricional e imunológico consumido em quantidades suficientes pelos recém-nascidos [2, 27]. O aleitamento materno fortalece a imunidade, mantém o crescimento e desenvolvimento normal, melhora o processo digestivo no sistema gastrintestinal, favorece o vínculo mãe-filho e facilita o desenvolvimento emocional, cognitivo e do sistema nervoso $[3,5,7,8,27,28,31]$.

O incentivo ao aleitamento materno nos países desenvolvidos a partir do início da década de 1970 resultou no crescimento da pesquisa sobre o leite humano [33]. As nutrizes foram incentivadas a ordenhar e

\footnotetext{
1. Recebido para publicação em 30/05/2003. Aceito para publicação em 18/01/2005 (001142). Trabalho elaborado como parte da dissertação de mestrado em Tecnologia de Alimentos de J.L.P.CAVALCANTE, "Aspectos fisico-quimicos do leite humano ordenhado cru e congelado", Universidade Federal do Ceará, Fortaleza, 2001.

2. Laboratório de Laticinios. Departamento de Tecnologia de Alimentos. Universidade Federal do Ceará. Secretaria Municipal de Saúde - Fortaleza-CE. Rua Monsenhor Salazar, 709, São João do Tauapé. CEP 60130370. Fortaleza-CE. Telefones: (85) 214-4305, (85) 9994-0175. E-mail: cavalcantejlp@bol.com.br

4. Laboratório de Controle de Qualidade. Banco de Leite Humano da Maternidade Escola Assis ChateauBriand. Universidade Federal do Ceará. * A quem a correspondência deve ser enviada.
}

doar o excesso de leite produzido, ficando os bancos de leite humano responsáveis pela atividade de coleta, processamento e controle de qualidade de colostro e leite humano, para posterior distribuição [14, 24].

O leite humano cru (LHc), se não utilizado de imediato, deve ser armazenado a $4^{\circ} \mathrm{C}$ por até 12 horas ou a -10 a $-18^{\circ} \mathrm{C}$ por no máximo 15 dias $[11,16,24]$. Antes da pasteurização $\left(62,5^{\circ} \mathrm{C} / 30\right.$ minutos), o leite estocado deve ser submetido a testes microbiológicos e físicoquímicos para avaliação de sua qualidade [24].

O leite humano fisicamente é um conjunto de emulsão diluída, dispersão coloidal e solução rica em compostos orgânicos e inorgânicos. Suas características físico-químicas principais são pH, acidez titulável, osmolalidade, capacidade tamponante, viscosidade, gravidade específica e condutividade térmica $[19,22]$. Sobrecargas ácidas ou básicas do leite humano resultam em acidose ou alcalose metabólica e a sua utilização pode causar enterocolite necrosante em neonato prematuro e de muito baixo peso ao nascer [30].

A acidez titulável do leite humano fresco imediatamente após a ordenha encontra-se entre 3 e $6^{\circ} \mathrm{D}[22]$. No entanto, quando realizado o pool (produto resultante da mistura de doações) do LHOc, a acidez titulável encontrada é em torno de $1 \mathrm{mM} / \mathrm{L}(\mathrm{pH}=7,12)$ [30]. O leite humano ordenhado cru não congelado pode ser considerado inicialmente um alimento pouco básico, passando a levemente ácido (até o 21 o dia pós-parto), 
estabilizando-se entre neutro e levemente básico (até o 180 dia pós-parto) [26].

A conservação do $\mathrm{LHOc}$ à baixa temperatura afeta a acidez titulável. Quando a temperatura ambiente diminui, passando de $20^{\circ} \mathrm{C} / 3 \mathrm{~h}$ para $4^{\circ} \mathrm{C} / 48 \mathrm{~h}$ de armazenagem, a acidez titulável pode variar de 8 a $13^{\circ} \mathrm{D}$ ou mais. Sendo a concentração de ácido láctico invariável à baixa temperatura, a acidez Dornic poderá ser diretamente influenciada pela concentração de ácidos graxos não esterificados de cadeia longa, por exemplo, ácido oléico $[16,22,25]$. O pH do leite humano ordenhado encontrase entre 5,47 e 7,84, e varia diretamente com as semanas de lactação e indiretamente com o percentual lipídico [9, 14, 15, 20]. Como metade do valor energético do leite humano é oriundo dos lipídios [28, 31], seria coerente afirmar que quanto maior a concentração de gordura total maior seria a possibilidade do leite desenvolver acidez elevada.

O crematócrito é um micrométodo rápido através do qual se determina a quantidade de creme e se estima a concentração de gordura e o conteúdo energético de uma amostra de leite humano. A distribuição de lipídios pode variar de 1 a $24 \%$. O leite humano ordenhado contém, aproximadamente, $40 \mathrm{~g}$ de gordura/Litro e 700Kcal/Litro. Até a $10^{\text {a }}$ semana do pós-parto, os lipídios mantêm-se constantes em torno de 6,4\%; a partir da $11^{\text {a }}$ semana pós-parto, elevam-se para $7,1 \%$, mantendo-se estáveis até a $62^{\text {a }}$ semana $[9,14,15,20]$.

Como o controle físico-químico do leite humano ordenhado cru requer métodos rápidos, práticos e com baixo custo operacional, o Centro de Referência Nacional dos Bancos de Leite Humano do Instituto Fernandes Figueira da Fundação Osvaldo Cruz (RNBLH/IFF/FIOCRUZ) vem promovendo estudos que visam desenvolver metodologias alternativas para o controle de qualidade do leite humano dos BLH do Brasil [24]. O estudo de ALMEIDA [1], realizado em amostras de LHOc de 19 nutrizes, revelou que o $\mathrm{pH}$ e a AT variaram, respectivamente, entre 6,8 a $7,7(7,3 \pm 0,2)$ e 3,5 a $10,5^{\circ} \mathrm{D}\left(5,6 \pm 1,0^{\circ} \mathrm{D}\right)$, dados semelhantes aos encontrados por HAMOSH et al. [17]. Porém, tais estudos foram realizados com amostras de leite humano avaliados imediatamente após a ordenha.

Como não existem na literatura especializada, dados sobre a acidez Dornic de leite humano ordenhado cru congelado e sua relação com o binômio tempo/temperatura e nem com os teores de creme, gordura total e valor energético, este estudo foi desenvolvido para avaliar a determinação da acidez titulável como ferramenta para selecionar amostras de leite humano destinado ao consumo nos bancos de leite. O comportamento dos teores de creme, gordura total e valor energético das amostras com acidez igual ou acima de $7^{\circ} \mathrm{D}$, após 15 dias de congelamento também foram averiguados.

\section{2 - MATERIAL E MÉTODOS}

\section{1 - Amostras}

O estudo foi realizado com amostras de leite humano ordenhado cru doadas por mães nutrizes que ti- nham feito ordenha manual em domicílio ou na sala de coleta de leite humano da Maternidade Escola Assis Chateaubriand (MEAC). As amostras domiciliares após a coleta foram colocadas em frascos esterilizados, fechadas e rotuladas contendo nome da mãe doadora, data da coleta e idade do recém-nascido. Em seguida, as amostras foram pré-estocadas em congeladores domésticos por 15 dias no máximo, até que as mesmas fossem recolhidas por funcionários do Banco de Leite Humano da Maternidade Escola Assis ChateaubriandUniversidade Federal do Ceará (BLH/MEAC/UFC) ou por policiais do Corpo de Bombeiros devidamente treinados. As amostras foram transportadas em caixas isotérmicas das casas das doadoras e da sala de coleta da MEAC até o BLH/MEAC/UFC onde foram selecionadas, classificadas, reenvazadas e retiradas alíquotas para testes físico-químicos e microbiológicos antes de serem pasteurizadas, conforme recomendação da Rede Nacional de Bancos de Leite Humano [24].

Em uma primeira etapa, avaliou-se todo o leite do BLH/MEAC/UFC coletado de setembro a dezembro de 2000 ( $n=4204)$, que serviu como controle da acidez titulável, em graus Dornic $\left({ }^{\circ} \mathrm{D}\right)$. Paralela a esta e durante o mesmo período, avaliou-se o teor de creme (\%), gordura total (\%) e valor energético (Kcal/Litro) de uma população ( $n=3887)$ menor, pois 317 das 4204 amostras foram perdidas e não utilizadas.

Na segunda etapa, procedida em abril de 2001, avaliou-se o teor de creme (\%), gordura total (\%) e valor energético (Kcal/Litro) de 66 amostras de leite humano ordenhado com acidez titulável $\geq 7^{\circ} \mathrm{D}$, oriundas do $\mathrm{BLH} / \mathrm{MEAC} / \mathrm{UFC}$. Cada amostra foi analisada duas vezes: teste 1 (primeira identificação) e teste 2 (segunda identificação). Todas as amostras após o teste 1 foram novamente congeladas em congelador doméstico onde o teste 2 foi executado 15 dias após o teste 1 , tudo dentro do mês de abril. A temperatura do congelador variou de $-10^{\circ}$ a $-18^{\circ} \mathrm{C}$ e foi monitorada duas vezes ao dia por meio de termômetros de mínima e máxima. O congelamento e descongelamento e as análises foram realizados conforme recomendado pela RNBLH [24].

\section{2 - Análises físico-químicas}

O teor de creme, gordura total e valor energético foram estipulados conforme o método de LUCAS et al. [20], adaptado de FLEET \& LINZELL [13], também conhecido como técnica do crematócrito.

A acidez titulável foi medida em graus Dornic $\left(\mathrm{D}^{\circ}\right)$ e determinada conforme descrito por FERREIRA [12], pelo MINISTÉRIO DA AGRICULTURA [23] e por ALMEIDA [1], adaptando-se a técnica usada em leite de vaca para leite humano.

\section{3 - Análise estatística dos resultados}

As análises estatísticas incluíram análise descritiva, análise de correlação e testes "t". Foi usado o teste "t" pareado para comparação dos resultados relativos as mesmas amostras no teste 1 e teste 2 . O nivel 
de significância estatística considerado foi de $5 \%$ ou menor $(\mathrm{p}<0,05)$.

\section{3 - RESULTADOS E DISCUSSÃO}

Considerando a primeira etapa do estudo, com a população de $n=4204$, a acidez Dornic variou de 0,5 a $21^{\circ} \mathrm{D}$. Os resultados da Tabela 1 mostram que 91,4\% dos leites $(\mathrm{n}=3844)$ possuíam acidez titulável $\leq 7^{\circ} \mathrm{D}$ e, apenas, $8,6 \%$ $(\mathrm{n}=360)$ apresentaram acidez titulável $>7^{\circ} \mathrm{D}$. Os teores de creme, gordura total e valor energético da população estudada $(n=3887)$ estão resumidos na Tabela 2.

TABELA 1. Acidez titulável $\left(D^{\circ}\right)^{2}$ da população total de leite humano ordenhado $\mathrm{cru}^{1}$.

\begin{tabular}{|c|c|c|c|}
\hline $\mathrm{N}^{\circ}$ de Amostras & Acidez Titulável $\left({ }^{\circ} \mathrm{D}\right)$ & $\%$ & $\%$ Cumulativo \\
\hline 7 & 0,5 & 0,15 & 0,15 \\
\hline 242 & 1,0 & 5,75 & 5,90 \\
\hline 493 & 1,5 & 11,70 & 17,60 \\
\hline 758 & 2,0 & 18,00 & 35,60 \\
\hline 518 & 2,5 & 12,30 & 47,90 \\
\hline 667 & 3,0 & 15,85 & 63,75 \\
\hline 305 & 3,5 & 7,25 & 71,00 \\
\hline 262 & 4,0 & 6,20 & 77,20 \\
\hline 118 & 4,5 & 2,80 & 80,00 \\
\hline 152 & 5,0 & 3,60 & 83,60 \\
\hline 86 & 5,5 & 2,04 & 85,64 \\
\hline 96 & 6,0 & 2,28 & 87,92 \\
\hline 76 & 6,5 & 1,80 & 89,72 \\
\hline 71 & 7,0 & 1,68 & 91,40 \\
\hline 19 & 7,5 & 0,45 & 91,85 \\
\hline 51 & 8,0 & 1,20 & 93,05 \\
\hline 60 & 8,5 & 1,40 & 94,45 \\
\hline 42 & 9,0 & 0,99 & 95,44 \\
\hline 27 & 9,5 & 0,64 & 96,08 \\
\hline 49 & 10,0 & 1,16 & 97,24 \\
\hline 22 & 10,5 & 0,50 & 97,74 \\
\hline 15 & 11,0 & 0,35 & 98,09 \\
\hline 10 & 11,5 & 0,23 & 98,32 \\
\hline 22 & 12,0 & 0,50 & 98,82 \\
\hline 6 & 12,5 & 0,14 & 98,96 \\
\hline 9 & 13,0 & 0,20 & 99,16 \\
\hline 12 & 13,5 & 0,28 & 99,44 \\
\hline 10 & 14,0 & 0,23 & 99,67 \\
\hline 3 & 14,5 & 0,07 & 99,74 \\
\hline 5 & 15,0 & 0,10 & 99,84 \\
\hline 1 & 15,5 & 0,02 & 99,86 \\
\hline 2 & 16,0 & 0,04 & 99,90 \\
\hline 2 & 16,5 & 0,04 & 99,94 \\
\hline 2 & 19,0 & 0,04 & 99,98 \\
\hline 1 & 21,0 & 0,02 & 100 \\
\hline 4204 & TOTAL & 100 & - \\
\hline
\end{tabular}

${ }^{1} \mathrm{BLH} / \mathrm{MEAC} / \mathrm{UFC}$. Setembro a dezembro. 2000.

$2^{\circ} \mathrm{D}$ : graus Dornic.

No que se refere à segunda etapa do estudo, todas as amostras de LHOc do teste 1 e teste 2 apresentaram acidez titulável entre 7,0 e $19,0^{\circ} \mathrm{D}\left(10,17 \pm 2,26^{\circ} \mathrm{D}\right)$, mediana $\left(10^{\circ} \mathrm{D}\right)$, moda $\left(12^{\circ} \mathrm{D}\right)$, coeficiente de variação $(22,28 \%)$ e amplitude total $\left(12^{\circ} \mathrm{D}\right)$. Conforme verificado na Tabela 3, os teores de creme, gordura total e valor energético variaram quando se avaliou o teste 1 com o teste 2 . O teor de creme de 59,09\% das amostras $(n=39)$ foi reduzido após 15 dias de congelamento com perdas variando de 0,1 a 4,55\%. Cerca de 63,63\% das amostras $(n=42)$ apresentaram redução no teor de gordura total depois de 15 dias de congelamento, de 0,07 a 3,08\%. Também o valor energético de $60,6 \%$ das amostras $(n=40)$ diminuiu após 15 dias de congelamento, variando de 10 a 300Kcal/Litro. Todas essas reduções foram significativas $(p<0,05)$. Uma correlação estatisticamente significante também foi encontrada entre as duas determinações do crematócrito nesta segunda etapa $(\mathrm{r}=0,88)$ e as análises de regressão forneceram a seguinte equação de predição entre o crematócrito do teste 1 (X) e do teste $2(\mathrm{Y})$ : $\mathrm{Y}=0,95 \mathrm{X}-0,42$.

TABELA 2. Teor de creme, gordura total e valor energético da população total de leite humano ordenhado cru $(\mathrm{N}=3887)^{6}$.

\begin{tabular}{cccccc}
\hline & $\mathrm{X} \pm \mathrm{sd}^{1}$ & $\mathrm{Md}^{2}$ & $\mathrm{Mo}^{3}$ & $\mathrm{CV}^{4}$ & $\mathrm{~A}^{5}$ \\
\hline $\begin{array}{c}\text { Teor de Creme } \\
(\%)\end{array}$ & $4,90 \pm 0,25$ & 4,80 & 3,20 & 5,05 & 26,4 \\
$\begin{array}{c}\text { Gordura Total } \\
(\%)\end{array}$ & $4,49 \pm 0,26$ & 4,39 & 2,79 & 5,92 & 26,4 \\
$\quad$ & & & & & \\
$\quad$ Valor & & & & & \\
$\begin{array}{c}\text { Energético } \\
(\text { Kcal / L })\end{array}$ & $617,47 \pm 17,37$ & 610,64 & 503,76 & 2,81 & 1763,52 \\
& & & & &
\end{tabular}

${ }^{6} \mathrm{BLH} / \mathrm{MEAC} / \mathrm{UFC}$. Setembro a dezembro. 2000

${ }^{1} \mathrm{X} \pm \mathrm{sd}=$ média mais desvio padrão $\left(\mathrm{em}{ }^{\circ} \mathrm{D}\right) ;{ }^{2} \mathrm{Md}=\operatorname{mediana}\left(\mathrm{em}{ }^{\circ} \mathrm{D}\right) ;{ }^{3} \mathrm{Mo}=\operatorname{moda}(\mathrm{em}$ $\left.{ }^{\circ} \mathrm{D}\right) ;{ }^{4} \mathrm{CV}=$ coeficiente de variação $(\mathrm{em} \%) ;{ }^{5} \mathrm{~A}=$ amplitude total $\left(\mathrm{em}{ }^{\circ} \mathrm{D}\right)$.

TABELA 3. Teores de creme, gordura total e valor energético das amostras de leite humano ordenhado cru com acidez titulável $\geq 7,0^{\circ} \mathrm{D}(\mathrm{n}=66)$, realizada durante os Testes 1 e $2^{6}$.

\begin{tabular}{|c|c|c|c|c|c|c|c|c|c|c|}
\hline & & & este 1 & & & & & este 2 & & \\
\hline & $X \pm s d^{1}$ & $\mathrm{Md}^{2}$ & $\mathrm{Mo}^{3}$ & $\mathrm{CV}^{3}$ & $A^{5}$ & $X \pm s d$ & Md & Mo & $\mathrm{CV}$ & A \\
\hline $\begin{array}{c}\text { Teor de } \\
\text { Creme } \\
(\%)\end{array}$ & $\begin{array}{c}6,45 \pm \\
2,28\end{array}$ & 5,80 & 5,0 & 35,43 & 17,80 & $\begin{array}{c}5,79 \pm \\
2,57\end{array}$ & 5,15 & 3,20 & 44,44 & 16,30 \\
\hline $\begin{array}{c}\text { Gordura } \\
\text { Total } \\
(\%)\end{array}$ & $4,0 \pm 1,81$ & 3,70 & 3,02 & 45,40 & 12,20 & $\begin{array}{c}3,49 \pm \\
1,76\end{array}$ & 3,11 & 1,78 & 50,49 & 11,16 \\
\hline $\begin{array}{c}\text { Valor } \\
\text { Energético } \\
\text { (Kcal / L) }\end{array}$ & $\begin{array}{c}716,27 \pm \\
176,59\end{array}$ & 670 & 620 & 24,65 & 1183 & $\begin{array}{c}666,82 \pm \\
171,90\end{array}$ & 630 & $\begin{array}{l}490 \\
510\end{array}$ & 25,77 & 1090 \\
\hline
\end{tabular}

6BLH/MEAC/UFC. Abril. 2001

$1 \mathrm{X} \pm \mathrm{sd}=$ média mais desvio padrão $\left(\mathrm{em}{ }^{\circ} \mathrm{D}\right) ;{ }^{2} \mathrm{Md}=\operatorname{mediana}\left(\mathrm{em}{ }^{\circ} \mathrm{D}\right) ;{ }^{3} \mathrm{Mo}=\operatorname{moda}(\mathrm{em}$ $\left.{ }^{\circ} \mathrm{D}\right) ;{ }^{4} \mathrm{CV}=$ coeficiente de variação $(\mathrm{em} \%) ;{ }^{5} \mathrm{~A}=$ amplitude total $\left(\mathrm{em}{ }^{\circ} \mathrm{D}\right)$.

O leite é um sistema tamponante com uma baixa concentração de íon hidrogênio livre e a quantidade total de ácido pré-formado, somente pode ser obtida pela medida da acidez titulável e não através do $\mathrm{pH}$ [4]. A acidez titulável mede parte da carga ácida total do leite $[22,30]$. Segundo HARRISON \& PEAT [18], a acidez titulável do leite é o volume de álcali requerido a fim de elevar o $\mathrm{pH}$ de sua concentração inicial para o $\mathrm{pH}=7,45$, usando $0,25 \mathrm{~mL} /$ Litro de $\mathrm{NaHCO}_{3}$. Pode ser expressa em mmol/Litro (mM/L), mEq/litro (mEq/L), graus Dornic $\left({ }^{\circ} \mathrm{D}\right)$ ou em graus Soxhlet-Henkel ( $\left.{ }^{\circ} \mathrm{S} . \mathrm{H}.\right)$ [4, 18, 19, 32]. 
TABELA 4. Médias e desvios padrões dos teores de creme, gordura total e valor energético por número de amostras de leite humano ordenhado cru com acidez titulável $\geq 7,0^{\circ} \mathrm{D}(\mathrm{n}=66)$, para os Testes 1 e $2^{1}$.

\begin{tabular}{|c|c|c|c|c|c|c|c|}
\hline \multirow[b]{2}{*}{$\begin{array}{l}\text { Acidez } \\
\text { Titulável } \\
\left({ }^{\circ} D\right)\end{array}$} & \multirow[b]{2}{*}{$\begin{array}{c}\text { Número } \\
\text { De } \\
\text { Amostras }\end{array}$} & \multicolumn{3}{|c|}{ Teste 1} & \multicolumn{3}{|c|}{ Teste 2} \\
\hline & & $\begin{array}{c}\text { Teor de } \\
\text { Creme } \\
(\%)\end{array}$ & $\begin{array}{c}\text { Gordura } \\
\text { Total } \\
(\%)\end{array}$ & $\begin{array}{c}\text { Valor } \\
\text { Energético } \\
\text { (Kcal / L) }\end{array}$ & $\begin{array}{c}\text { Teor de } \\
\text { Creme } \\
(\%)\end{array}$ & $\begin{array}{c}\text { Gordura } \\
\text { Total } \\
(\%)\end{array}$ & $\begin{array}{c}\text { Valor } \\
\text { Energético } \\
\text { (Kcal / L) }\end{array}$ \\
\hline 7,0 & 7 & $6,05 \pm 1,30$ & $3,73 \pm 0,88$ & $690 \pm 84,26$ & $4,73 \pm 1,50$ & $2,83 \pm 1,02$ & $602 \pm 98,78$ \\
\hline 7,5 & 3 & $5,30 \pm 0,30$ & $3,22 \pm 0,20$ & $640 \pm 20,00$ & $3,70 \pm 0,86$ & $2,12 \pm 0,59$ & $533 \pm 57,73$ \\
\hline 8,0 & 6 & $6,71 \pm 0,60$ & $4,18 \pm 0,41$ & $735 \pm 41,83$ & $5,63 \pm 1,19$ & $3,45 \pm 0,81$ & $661 \pm 82,56$ \\
\hline 8,5 & 2 & $4,90 \pm 0,14$ & $2,95 \pm 0,09$ & $615 \pm 7,07$ & $5,25 \pm 0,78$ & $3,19 \pm 0,53$ & $635 \pm 49,50$ \\
\hline 9,0 & 7 & $5,74 \pm 1,48$ & $3,52 \pm 1,01$ & $668 \pm 98,39$ & $5,40 \pm 1,99$ & $3,29 \pm 1,36$ & $647 \pm 133,2 E$ \\
\hline 9,5 & 7 & $6,01 \pm 1,63$ & $3,70 \pm 1,12$ & $687 \pm 109,95$ & $5,61 \pm 2,91$ & $3,43 \pm 1,99$ & $660 \pm 196,47$ \\
\hline 10,0 & 3 & $7,76 \pm 6,48$ & $4,91 \pm 4,43$ & $806 \pm 430,15$ & $7,83 \pm 2,29$ & $4,95 \pm 1,56$ & $806 \pm 150,7 \mathrm{C}$ \\
\hline 10,5 & 3 & $7,50 \pm 3,29$ & $4,72 \pm 2,23$ & $786 \pm 219,39$ & $6,13 \pm 1,64$ & $3,79 \pm 1,13$ & $670 \pm 88,88$ \\
\hline 11,0 & 6 & $5,25 \pm 0,53$ & $3,19 \pm 0,37$ & $636 \pm 36,15$ & $4,28 \pm 1,24$ & $2,53 \pm 0,85$ & $573 \pm 82,38$ \\
\hline 11,5 & 6 & $6,33 \pm 1,13$ & $3,93 \pm 1,02$ & $708 \pm 99,08$ & $6,15 \pm 1,60$ & $3,80 \pm 1,14$ & $696 \pm 105,96$ \\
\hline 12,0 & 8 & $6,51 \pm 2,08$ & $4,05 \pm 1,42$ & $718 \pm 138,61$ & $5,70 \pm 0,69$ & $3,50 \pm 0,47$ & $666 \pm 48,38$ \\
\hline 12,5 & 2 & $8,55 \pm 0,78$ & $5,44 \pm 0,53$ & $855 \pm 49,50$ & $6,85 \pm 2,47$ & $4,88 \pm 1,70$ & $745 \pm 162,6 \varepsilon$ \\
\hline 13,0 & 2 & $4,88 \pm 0,28$ & $2,88 \pm 0,20$ & $605 \pm 21,21$ & $4,75 \pm 1,91$ & $2,84 \pm 1,31$ & $600 \pm 127,2 \varepsilon$ \\
\hline 13,5 & 2 & $5,40 \pm 1,55$ & $3,29 \pm 1,06$ & $645 \pm 106,06$ & $5,20 \pm 2,97$ & $3,15 \pm 2,03$ & $630 \pm 197,9 \subseteq$ \\
\hline 15,5 & 1 & $\mathrm{ND}^{2}$ & ND & ND & ND & ND & ND \\
\hline 19,0 & 1 & ND & ND & ND & ND & ND & ND \\
\hline
\end{tabular}

${ }_{1}^{1}$ BLH /MEAC/UFC. Abril. 2001.

${ }^{2} \mathrm{ND}=$ não determinável

A acidez titulável é mais sensivel ao conteúdo total de solutos e pode estar diretamente relacionada ao aumento da densidade calórica [22, 30].

Os dados para gordura total do LHOc (Tabela 2) são inferiores aos encontrados previamente, em 1991, por GOLDFARB \& SAVADOVE [15] (Média=6,6\%, Mediana $=6,0 \%$, Moda $=4 \%$ ) que também usaram o método do crematócrito. Como os referidos pesquisadores determinaram os lipídios no mesmo dia da coleta, o binômio tempo/temperatura deve ter influenciado nos resultados deste estudo. Considerando-se que quanto maior a concentração de lipídios menor é o pH do LHOc e maior é a acidez titulável, verifica-se que essa tendência não foi encontrada neste estudo (Tabelas 3 e 4). Na maioria dos leites naturais, o ácido titulável medido é principalmente o ácido cítrico que após ingerido e absorvido pelo intestino humano, é rapidamente metabolizado a $\mathrm{CO}_{2}$, não contribuindo, portanto, para a carga de ácido metabólico [4]. GOLDFARB \& SAVADOVE [15] registraram o pH de amostras de LHOc desnatado, previamente refrigeradas (1 a 36 horas), usando um pHmetro, enquanto que neste estudo, o $\mathrm{pH}$ não foi medido.

A redução nos valores do creme, mostrada na Tabela 3, após 15 dias foi similar aos encontrados por DE GROOT et al. [10]. O valor médio do crematócrito das amostras frescas foi significantemente maior do que nas amostras descongeladas. Já o coeficiente de variação foi significativamente menor nas amostras frescas do que nas amostras descongeladas $(p<0,05)$, similar ao encontrado neste estudo. Assim, o crematócrito medido nas amostras descongeladas pode resultar em baixos valores, provavelmente devido à lipólise do leite humano.
O aumento percentual do número de amostras com acide $>7^{\circ} \mathrm{D}$, de setembro a dezembro de 2000 , poderia ser devido ao não monitoramento das condições de transporte e temperatura interna das caixas isotérmicas, conduzidas das casas das mães doadoras até o BLH [22], pois as temperaturas das amostras não são determinadas no momento da recepção. A elevada temperatura ambiental de Fortaleza $\left(27\right.$ a $\left.31^{\circ} \mathrm{C}\right)$ aumentaria, progressivamente, a temperatura interna da caixa e do leite humano, estimulando a ação fermentativa das bactérias do LHOc (saprófitas e patogênicas) e de suas respectivas enzimas (proteases, lipases e descarboxilases) [21]. Devido a isso, a degradação dos triacilgliceróis pelas lipases produziriam ácidos graxos não esterificados (ácidos graxos livres) os quais elevariam a concentração de íons $\mathrm{H}^{+}$do leite humano, reduziriam o $\mathrm{pH}$ e aumentariam a acidez titulável. Mesmo mantendo a temperatura do leite humano entre 4 e $8^{\circ} \mathrm{C}$ por até 30 horas, evitando a multiplicação de bactérias, inclusive das psicotróficas, as atividades das lipases seriam apenas reduzidas [21]. Estudos realizados por HAMOSH et al. [17] demonstraram que o $\mathrm{pH}$ do LHOc diminui bastante após estocagem a $38^{\circ} \mathrm{C} / 24$ horas mas não em temperaturas inferiores $\left(15\right.$ e $\left.25^{\circ} \mathrm{C}\right)$. Esses mesmos pesquisadores mostraram que após 24 horas de estocagem a $15-38^{\circ} \mathrm{C}, 85-91 \%$ da atividade inicial da BSDL (lipase dependente de sais biliares) foi mantida mas quase $100 \%$ da atividade da LPL (lipoproteína lipase) foi perdida. Portanto, a redução do $\mathrm{pH}$ e o aumento da acidez titulável parecem não afetar a atividade dessas enzimas, as quais são estáveis a $\mathrm{pH}>3,5$.

Outro fator que poderia ter causado as perdas da LPL seria o não monitoramento da temperatura dos congeladores das geladeiras domésticas nas próprias casas das doadoras [21]. Como tais eletrodomésticos possuem apenas termostato, seria impossivel afirmar que os frascos com LHOc permaneceram com as temperaturas recomendadas $\left(4^{\circ} \mathrm{C} / 24\right.$ horas ou $-10^{\circ} \mathrm{C}$ a $-18^{\circ} \mathrm{C} / 15$ dias) [22, 24]. Também, é possivel que algumas doadoras não tenham mantido os frascos com leite humano dentro dos padrões térmicos estipulados pela RNBLH, mesmo sendo bem orientadas por funcionários do banco de leite e por policiais do Corpo de Bombeiros. Portanto, efetivar um controle de qualidade dinâmico nos BLH é essencial e prioritário para a segurança nutricional do leite humano e dos neonatos $[1,2,24]$. Certamente, estudos posteriores, comparando a acidez titulável do LHO cru com o seu armazenamento residencial e transporte ao banco de leite poderá ser executado.

O binômio tempo-temperatura de conservação teve influência sobre a quantidade de creme, gordura total e valor energético do LHOc. Observou-se que após os 15 dias de congelamento das amostras, houve redução significativa do teor de creme, gordura total e valor energético. Estima-se que a lipólise, mesmo em tais condições, continuaria a ocorrer [6, 17]. MORERA-PONS, CASELLOTE-BARGALLÓ \& LÓPEZ-SABATER [25] demonstraram que em amostras de LHO estocadas a - 
$20^{\circ} \mathrm{C} / 4$ meses e previamente aquecidas $\left(80^{\circ} \mathrm{C} / 1,5 \mathrm{mi}-\right.$ nutos), a presença de ácidos graxos livres e monoacilgliceróis foi detectada, sugerindo que as lipases (como a BSDL) permanecem estáveis e ativas nessa temperatura. Porém, quando outras amostras dos mesmos leites foram estocadas a $-80^{\circ} \mathrm{C}$ por 4 meses, o perfil de triacilgliceróis foi mantido e nenhum ácido graxo livre, monoacilgliceróis e diacilgliceróis foi detectado, sugerindo que a conservação à baixa temperatura com congelamento rápido preserva a estrutura dos triacilgliceróis do leite humano por até 120 dias, e inativa as lipases. No entanto, o uso desses procedimentos para bancos de leite parece ser inviável, muito oneroso e inexeqüivel à nossa realidade.

A pasteurização do leite humano ordenhado cru com acidez titulável acima de $7^{\circ} \mathrm{D}$ não irá melhorar a qualidade do leite. Primeiro, a pasteurização padrão adotada $\left(62,5^{\circ} \mathrm{C} / 30\right.$ minutos $)$ tem como finalidade eliminar todos os microrganismos patogênicos e $90 \%$ da flora saprófita do LHOc [24]. E sendo a pasteurização um processo físico e a neutralização da acidez, um processo químico, o calor não exerceria ação neutralizante sobre a acidez do leite humano [24, 29].

Conforme determinado neste estudo, é lícito afirmar que o leite humano ordenhado deveria ser pasteurizado se a acidez Dornic fornecesse valores abaixo de $7^{\circ} \mathrm{D}$. Mesmo a afirmação anterior não sendo definitiva, acredita-se que o leite humano ordenhado apto para consumo poderá ter valores para acidez titulável acima de $7^{\circ} \mathrm{D}$. O Journal Officiel de la République Française $(27$ de agosto de 1954), citado por LUZEAU, BARROIS \& ODIEURE [22], mostra que qualquer amostra apresentando acidez titulável superior a $13^{\circ} \mathrm{D}$ é imprópria para o consumo. Conforme os estudos preliminares de LUZEAU, BARROIS \& ODIEURE [22], o leite apto para consumo poderia ter acidez titulável aceitável entre 8 a $13^{\circ} \mathrm{D}$.

\section{4 - CONCLUSÕES}

O aproveitamento do leite humano ordenhado cru com $\mathrm{AT} \geq 7^{\circ} \mathrm{D}$ para neonatos é inviável por dois motivos: (1) pela redução no teor de creme, gordura total e valor energético e (2) pelo risco de causar acidose ou alcalose metabólica e enterocolite necrosante. Neste caso, é recomendado desprezar totalmente o leite humano com acidez elevada. O uso do teste da acidez titulável constitui uma ferramenta no controle de qualidade do leite humano ordenhado cru. A possibilidade de alguma forma de neutralizar rapidamente ou evitar a acidez excessiva do leite humano ordenhado sem prejuízo no valor nutricional e imunológico, ainda constitui objeto de pesquisas futuras.

\section{5 - REFERÊNCIAS BIBLIOGRÁFICAS}

[1] ALMEIDA, J.A.G. Qualidade do leite humano coletado e processado em bancos de leite. Viçosa, MG, 1986, 84p. Dissertação de Mestrado. Departamento de Microbiologia Agrícula. Universidade Federal de Viçosa (UFV).
[2] ALMEIDA, J.A.G. Amamentação: um híbrido naturezacultura. Rio de Janeiro: Editora Fiocruz. 1999. 120p.

[3] ANDERSON, J.W.; JOHNSTONE, B.M.; RAMLEY, D.T. Breast-feeding and cognitive development: a metaanalysis. Am. J. Clin. Nutr., v. 70, p. 525-535, 1999.

[4] BERG, H.M.; SCOTT, P.H.; KENWARD, C.; SCOTT, P.; WHARTON, B.A. Milk pH, acid base status, and growth in babies. Arch. Dis. Child., v. 53, p. 926-930, 1978.

[5] BEZKOROVAINY, A. Probiotics: determinants of survival and growth in the gut. Am. J. Clin. Nutr. v. 73, p. 399-405, 2001. (Suplemento).

[6] BJÖRKSTEN, B.; BURGAN, L.G.; DECHÄTEAU, P.;FREDRIKZON, B.; GOTHEFORS, L.; HERNELL, O. Collecting and banking human milk: to heat or not to heat ? British Med. J., v. 281, p. 765-769, 1980.

[7] CAlHoun, D.A.; LUNOE, M.; DU, Y.; CHRISTENSEN, R.D. Granulocyte colony-stimulating factor is present in human milk and its receptor is present in human fetal intestine. Pediatrics. v. 105, n. 1, e7, 2000. Disponivei em: <http:// www. pediatrics.org>. Acesso em: 30 jan. 2001.

[8] Clemens, J.; ELYAZEED, R.A.; RAO, M.; SAVARINO, S.; MORSY, B.Z.; KIM, Y.; WIERZBA, T.; NAFICY, A. LEE, Y.J. Early inition of breastfeeding and the risk of infant diarrhea in Rural Egypt. Pediatrics. v. 104, n. 1, e3, 1999. Disponível em: <http:// www.pediatrics.org>. Acesso em: 14 fev. 2000.

[9] COLlaRES, F.P.; GONÇALVES, C.V.; FERREIRA, J.S. Creamatocrit as a rapid method to estimate the contents of total milk lipids. Food Chemistry, v. 60, p. 465467, 1997.

[10] DE GROOT, S.D.W.; KRAMER, L.; BULUX, J.; SOLOMONS, N.W.; GREEN, M.H.; WEST, C.E. Effect of freezing on the creamatocrit values of breast milk samples. FASEB J., v. 12, p. A538 (3127), 1998.

[11] DHAR, J.; DAVIDSON, A.G.F.; MARTINEZ, F.E.; BARR, S.; DESAL, I.D.; NAKAI, S. Ultrasonication, lyophilization, freezing and storage effects on fat loss during mechanical infusion of expressed human milk. J. Food Sci, v. 60, p. 375-377; 394, 1995.

[12] FERREIRA, C.L.L.F. Acidez em leite e produtos lácteos. Viçosa, MG: Imprensa Universitária, UFV. 1981. 75 p.

[13] FLEET, I.R.; LINZELL, J.L. A rapid method of estimating fat in vary small quantities of milk. J. Physiol., v. 175, p. 15P-17P, 1964.

[14] GIBBS, J.H.; FISHER, C.; BHATTACHARYA, S.; GODDARD, P.; BAUM, J.D. Drip breast milk: its composition, collection and pasteurization. Early Hum. Dev., v. 1, p. 227-245, 1977.

[15] GOLDFARB, M.F.; SAVADOVE, M.S. Creamatocrit and $\mathrm{pH}$ measurements of human milk. J. Pediatr. Gastroenterol. Nutr., v. 12, p. 142-143, 1991.

[16] HAMOSH, M.; ElliS, L.A.; POLLOCK, D.R.; HENDERSON, T.R.; HAMOSH, P. Breastfeeding and the working mother: effect of time and temperature of short-term storage on proteolysis, lipolysis, and bacterial growth in milk. Pediatrics, v. 97, p. 492498, 1996.

[17] HAMOSH, M.; HENDERSON, T.R.; ELLIS, L.A.; MAO, J.I. Digestive enzymes inhuman milk: stability as suboptimal sorage temperatures. J. Pediatr. Gastroenterol. Nutr., v. 24, p. 38-43, 1997.

[18] HARRISON, V.C.; PEAT, G. Significance of milk pH in newborn infants. British. Med. J., v. 4, p. 515-518, 1972. 
[19] JENNESS, R.; SHIPE Jr, W.F.; SHERBON, J.W. Physical properties of milk. In: WEBB, B.H., JOHNSON, A.H.; ALFORD, J.Á. (Editores). Fundamentals of dairy chemistry. $2^{\text {nd }}$ ed. Westport, Connecticut (USA): The Avi Publishing Company Inc, 1974. p. 402-441.

[20] LUCAS, A.; GIBBS, J.A.H.; LYSTER, R.L.J.; BAUN, J.D. Creamatocrit: simple clinical technique for estimating fat concentration and energy value of human milk. British. Med. J., v. 1, p. 1018-1020, 1978.

[21] LUCAS, A.; ROBERTS, C.D. Bacteriological quality control in human milk-banking. British. Med. J., v. 1, p. 80-82, 1979.

[22] LUZEAU, R.; BARROIS, V.; ODIEVRE, M. Acides gras non estérifiés et acidité titrable du lait maternel. Arch. Fr. Pediatr., v. 40, p. 449-451, 1983.

[23] MINISTÉRIO DA AGRICULTURA. Leite fluído. In: Métodos analiticos oficiais para controle de produtos de origem animal e seus ingredientes. Brasília, DF: Imprensa da União, 1981. cap. 14. p. 52-63

[24] MINISTÉRIO DA SAÚDE. Recomendações técnicas para o funcionamento de bancos de leite humano. 4a ed. Brasília, DF, 2001. Série A, n. 117, 48 p.

[25] MORERA-PONS, S.; CASTELLOTE-BARGALLÓ, A.I.; LÓPEZ-SABATER, M.C. Evaluation by highperformance liquid chromatography of the hydrolysis of human milk triacylglycerides during storage at low temperatures. J. Chromatogr. A., v. 823, p. 467-474, 1998.

[26] MORRISS Jr, F.H.; BREWER, E.D.; SPEDALE, S.B.; RIDDLE, L.; TEMPLE, D.M.; CAPRIOLI, R.M.; WEST, M.S. Relationship of human milk $\mathrm{pH}$ during curse of lactation to concentrations of citrate and fatty acids. Pediatrics, v. 78, p. 458-464, 1986.
[27] NÓBREGA, F.J., CAMPOS, A.L.R. Distúrbios nutricionais e fraco vínculo mãe/filho. Rio de Janeiro, RJ: Revinter. 1996. 236 p.

[28] REYNOLDS, A. Breastfeeding and brain development. Ped. Clin. North Am., v. 48, p. 159-171, 2001. Parte 1.

[29] ROSA, TC. Química geral pH. Goiânia (GO): UFG Editora. 1983. (Coleção Didática n. 6). 76 p.

[30] TOH, C.C., HO, N.K. pH, titratable acidity \& osmolality of human breast milk \& some infant milk formulae. J. Sing. Paediatr. Soc., v. 20, p. 88-92, 1978.

[31] UAUY, R., MENA, P. Lipids and neurodevelopment. Nutr .Rev., v. 59, p. 34-48, 2001. (Suplemento 2)

[32] VEISSEYRE, R. Caracteres, composición y estructura de la leche. In: . Lactología técnica. 1. ed. Zaragoza, España: Acribia, 1988. p.1-63.

[33] WRIGHT, AL. The rise of breastfeeding in the United States. Ped. Clin. North Am., v. 48, p. 1-12, 2001. (Parte 1).

\section{6 - AGRADECIMENTOS}

Agradecemos aos professores Dr. Joel Alves Lamounier, médico pediatra, Coordenador e Professor do Curso de Mestrado e Doutorado em Pediatria da UFMG e Dra. Regilda Saraiva dos Reis Moreira Araújo, nutricionista, Professor Adjunto do Departamento de Nutrição e Coordenadora do Curso de Nutrição / UFPI pelo auxílio na revisão e redação deste estudo; e ao Núcleo de Ensino e Pesquisa (NEP) da MEAC/UFC e pela Coordenação do BLH/MEAC/UFC por terem autorizado a realização deste trabalho. 